\title{
AMIGOS, O SUBLIME NÃO MORA NO ESPAÇO*
}

\author{
FRIEDRICH RATZEL
}

É um grande erro pensar que a religião, que concebeu e guiou no nível mais profundo da cultura toda via espiritual, tornou-se pobre e fraca, à medida que a arte e a ciência se liberaram de sua conduta. Quase não brilhou mais, por algum tempo, perante o lustre desses novos desdobramentos. Mas foi apenas um ofuscamento passageiro, sombra de nuvens. A ciência não subiu, de modo algum, cada vez e mais alto, e deixou a religião simplesmente cada vez mais afundada na planície mitológica; nem tampouco ficou a religião como um casulo, do qual a borboleta ciência se livrou. A ciência, desde que se tornou independente, não esclareceu o mistério de nossa existência; a inteligência, que trabalha com a indução e a experimentação, choca-se hoje com as mesmas fronteiras com que, por milhares de anos, o espírito explicou o enigma do mundo através de poemas mitológicos, e não há nenhum nível do conhecimento a que se tenha chegado que pudesse negar o direito do antigo conceito de um ente espiritual para além dessas fronteiras. Uma grande parte do trabalho intelectual dos mais diversos campos da ciência foi e é gasta no esforço de demonstrar um firme progresso para além do que se denomina de nível mitológico, de estabelecer o triunfo da ciência sobre a religião e de mostrar que a inteligência humana destronou Deus, ou que à natureza, ou a qualquer outro indeterminado conceito, se gostaria de dar uma posição de dominância. Mas em vão: precisamente o pensamento mais profundamente científico conduziu a Deus, a era da religião nunca terminou, nem nunca terminará, e o que se chama de idade da ciência não está acima de Deus, mas nele. É uma grande verdade no desenvolvimento do espírito da humanidade num todo, e na formação de cada ser isoladamente, que o progresso científico signifique simplificação e estreitamento, mas não enriquecimento ou ampliação. Ninguém duvidará que, com o progresso do conhecimento, o mundo tenha se ampliado tanto quanto possa ser expresso em números. As distâncias estelares do espaço e os necessários bilhões de anos de tempo cresceram até tornarem-se inimagináveis. Mas quanto mais extensamente o conhecimento penetrou nessas dimensões gigantescas, nossas idéias das condições e acontecimentos nas mesmas não se ampliaram conjuntamente. Ao contrário. Por não progredirem proporcionalmente àquele crescimento de massa e de números, ficaram relativamente menores. A astronomia não descobriu nenhum mundo novo, como costuma-se dizer, mas apenas outros, que são sempre os mesmos. A geologia não descobriu em todas as idades da história da Terra nenhum estrato novo, mas sim sempre o mesmo proveniente de lava, ou solidificada, ou transformada, ou inalterada. A história da vida tem desde os primeiros vestígios do cambriano (um dos mais antigos períodos da Terra) até o presente formas semelhantes; nenhum novo tipo de reino vegetal ou animal foi comprovado pela paleontologia: são sempre apenas novos ramos dos mesmos antiquíssimos caules, que nos recorda um salgueiro por sobre um regato, rico em nós e ramos, continuamente verdejante, com sempre novas varas pendentes. Quem admira a abundância de nomes da botânica e da zoologia sistemáticas pensa

\footnotetext{
* n Glauben und Wissen. Volkstümliche Blätter zur Vertiefung des Christlichen Weltbildes. Erster Jahr. Stuttgart (Januar) 1903. Heft 1, S. 19-22. (Helmolt, 1906; pp. 293-297).Tradução de Luciana de Lima Martins (mestre e doutora em Geografia pela UFRJ, desde 1999 trabalha como pesquisadora do Grupo de Geografia Social e Cultural de Royal Holloway, Universidade de Londres). Esta tradução contou com o apoio do prof. Ferdinand Reis, a quem a tradutora agradece, sem o que a tradução não se viabilizaria.
} 
primeiramente numa aparente variedade de criaturas, até que reconhece ser verdadeiro o contrário: algumas poucas formas primigênias numa abundância de variações dispersas, que, no fundo, têm pouquíssimas diferenças.

Assim o conhecimento do mundo (welterkenntnis) não foi enriquecido, mas simplificado pela representação do mundo (weltvorstellen) que produzimos. Os pensamentos, que para nós causariam a grandeza e o desenvolvimento do universo, são em menor quantidade e mais simples do que acreditávamos. Há no fundo o mesmo curso das coisas como em cada caso isolado em que perseguimos um fenômeno sobre espaços extensos ou através das imensas séries cronológicas: a grandeza do espaço e a duração do tempo não evitam que esse se atrofie conforme o entendemos. Nesse sentido, nada é mais instrutivo que o efeito de um dos maiores e, com razão, mais admiráveis descobrimentos no campo da ciência física: a análise espectral. Ela demonstrou uma unidade da matéria no espaço do mundo que não apenas simplificou extraordinariamente o mundo dos sóis, dos cometas, das nuvens cósmicas e das estrelas extintas, como também diminuiu, em medida ainda maior, perante nossos inteligentes olhos, a grandeza do mundo. $\mathrm{O}$ que significam essas distâncias estelares se, através delas, as diferentes características das matérias nelas dispersas não se mostram perceptíveis? As distâncias espaciais descem para um plano secundário, as distâncias temporais para um declínio fortuito. Já então Alexander von Humboldt viu nisto uma grandiosa simplificação da mecânica celeste, que não era, de modo algum, a distinguibilidade da matéria dos corpos celestes. Será que perdemos essa simplicidade? Não. A análise espectral, contra todas as previsões, enformou uma imagem simples de mundo, ao invés de múltipla. Um sol que é, na essência, da mesma matéria-prima de nosso planeta, da da multiplicidade das estrelas, cujos mais distantes sóis também constituem-se da mesma matéria, de tal forma que nos apresente apenas alguma graduação de seus diferentes estados de incandescência. Isto não é mais uma simplificação, trata-se de uma homogeneização. Já que encontramos sempre os mesmos elementos - desde as nebulosas até os meteoros -, há esta uniformidade pelo mundo todo, que nós denominamos nosso. E assim é também para nós, no fundo, o que aconteceu no estudo da vida, cuja tocha nos foi passada pela teoria evolucionista. Onde estão os estranhos e inconcebíveis animais e plantas dos primórdios do mundo, que se supôs outrora existirem, quando não havia ainda nenhum estudo sistemático dos vestígios préhistóricos? A paleontología não trouxe à luz mais nada disso: ela nos mostrou com certeza milhares de espécies e deixou ainda muitas sugeridas, mas isso tudo são novamente apenas leves variações de uma série de formas que também predominam na formação dos atuais mundos animal e vegetal. Não foi confirmado de modo algum nenhum tipo (forma), e é até mesmo possível que os protozoários, os radiolários, os articulados, os moluscos e os vertebrados, dos quais nossos mais antigos vestígios de vida descendem, desde há muito tempo estivessem sobre a Terra: esta existência remota dos vertebrados não foi demonstrada até hoje, porque seu esqueleto original era cartilaginoso, e não tinha a dureza dos ossos. E certamente um grande progresso que nós agora tenhamos pelo menos uma noção de grandeza espaço-temporal, na qual esse desdobramento vital foi consumado. Onde Buffon admitia alguns milênios, novos físicos alguns milhões de décadas, Lyell e Darwin algumas centenas de milhões de anos, não podemos retroceder a não menos de meio bilhão de anos atrás e quem sabe, um dia, os ultrapassaremos. Mas quão pouco nos impressiona essa grandeza numérica, se consideramos o que nela é novo ou diferente. Do início da vida estamos, por fim, aproximadamente tão longe dessa série cronológica quanto hoje; a superfície terrestre apresentava montanhas e mares como hoje, e os seixos rolados de quartzo do cambriano parecem ter sido depositados ontem pelas ondas, certamente iluminadas do mesmo modo por seu jovem sol e desenrolando-se como as ondas de hoje. É a mesma coisa, quando os astrônomos nos mostram, no limite do visível, nebulosas que são a Via Láctea. Sem querer, pensamos com Schüller: "Amigos, o sublime não mora no espaço!". As enormes distâncias estelares não incitam mais, uma vez que afloram sempre os mesmos materiais, formas 
e agrupamentos. Não é este céu estelar muito mais ilusoriamente parecido com uma gota d'água repleta de pequenos seres formigantes que se abrem para nosso olhar ao microscópio? Afastem-se esses seres orgânicos, que se importunam uns aos outros, coloquem-se entre eles grandes distâncias e se revelará um quadro aparentemente paralisado num imenso espaço. E, quando reflito sobre distâncias estelares após distâncias estelares, repete-se sempre e sempre a mesma coisa. E uma peregrinação pelo deserto, uma viagem marítima; longa, porém pobre.

Onde se encontra então o enriquecimento que tantos admitiram ser o último e mais alto fim da formação científica? Quem pensa que, através do acúmulo ininterrupto de conhecimentos, coleciona um tesouro sempre maior, deparar-se-á infalivelmente um dia com o fato de ter-se enganado: o volume de seus conhecimentos não aumenta, desvanece conjuntamente à medida que, se comprimindo com o acúmulo, se concentra. E como o derretimento da neve: a água, que então escorre, pesa tanto quanto a neve que dela resulta, como é também da mesma matéria; temse aí menos. Com a compressão foram embora os cristais, juntamente com o brilho e o vislumbre da neve. Resta, contudo, a clareza; mas, por intermédio dessa clareza, vemos sempre novamente as mesmas coisas e atrás de cada clareza sempre e sempre a mesma clareza e assim por diante. Assim é com os planetas, estrelas, nebulosas, infusórios, séries anuais: pensamos sempre mais para além deles e quando pensamos estar satisfeitos e cansados é sempre a mesma pequena margem da temporalidade tudo o que temos conosco, em que as "clarezas" de nossos conhecimentos seguem, onda após onda, o movimento de um oceano da eternidade. Pensávamos ter ampliado a terra prometida do saber em contrapartida, estreitou-se de todos os lados, e temos apenas terra bastante para nos mantermos em cima dela; e vice-versa, com todo aprofundamento e ampliação do saber, é cada vez mais potente o campo do desconhecido, da incerteza, e nunca amplia-se o do conhecimento. Por todos os caminhos da investigação abre-se o olhar para esse mar cinzento, que é, por todos os lados, o mesmo. Não é isso em que acreditávamos, em termos afastado até a invisibilidade, ao completo desaparecimento, o que muitos procuraram, em vão, na distância luminosa e remota do pensamento de Colombo e Magalhães? E então a eternidade banha nossos pés e quebram ondas por todos os lados como se nunca tivesse havido a riqueza do saber e a autoridade científica. Essa imagem do mundo não é diferente daquela da humanidade crepuscular, que não tinha ainda quase nenhuma ciência e cuja criação do mundo era encarada como uma quase vivência de ontem ou de anteontem. $\mathrm{O}$ finito não podia ser para ela menor, o infinito maior e mais perto do que se apresentava. E para nós, por outro lado, harmonizar com o infinito e ter modéstia perante esse mesmo infinito não parecem estar distantes. E, ao contrário, essa ligação entre nós e o infinito reluzente circundante, o indício distintivo da época a que chegou agora o desenvolvimento intelectual da humanidade. Os grandes naturalistas, que proferiram como soma de suas experiências que a verdadeira ciência não poderia afastar-se de Deus, conquistaram seu conhecimento em semelhante harmonia com o infinito, para ensinarem consequentemente que o mais alto dever da ciência deveria ser a vontade efetiva de esclarecimento. Pois, sem o olhar no infinito, não se equipara à realidade nenhuma imagem do mundo e nem é possível, portanto, nenhuma visão do mundo ( Weltanshauung) que resista. Uma verdade das coisas correspondente à visão do mundo não pode, por isso, ser erigida apenas sobre a ciência, mas deve fundar-se sobre a fé: tão certamente quão mais distante a ignorância circundante for afastada do enigmático recife de nossa existência e de nosso saber. 